\title{
Banco de Proteína: Fortalecimento da Agricultura Familiar na Comunidade do Amaragi no Município de Lagoa Seca-Paraíba
}

\author{
Viviane Galdino dos Santos ${ }^{1}$, Laura Ana Alves de Lima ${ }^{2}$, Bruna dos Santos Souza ${ }^{3}$, Deliane Andrade de Arruda ${ }^{4}$, \\ Vanderléia Galdino dos Santos 5
}

\author{
Universidade Estadual da Paraíba; ${ }^{1}$ viviane.galdino.pb@ hotmail.com; ${ }^{2}$ lauraanalima@ hotmail.com; \\ ${ }^{3}$ souza.brusbs@gmail.com; ${ }^{4}$ deliane.andrade@ hotmail.com; ${ }^{5}$ vander.vigaldino96@gmail.com.
}

\begin{abstract}
RESUMO: O presente trabalho visa relatar a experiência do projeto de extensão rural para os alunos da Universidade Estadual da Paraíba - Campus II, tendo por objetivo de contribuir com a implantação de um banco de proteína com leguminosas adaptadas as diferentes condições edafoclimáticas, no intuito de fortalecer a agricultura familiar na comunidade Amaragi, localizado na Zona Rural de Lagoa Seca/PB. Foram realizadas visitas de campo nas quais executaram a capina e o coroamento das leguminas com cobertura morta do banco de proteína já implantado na comunidade. As vivências das atividades contribuíram para a aprendizagem dos alunos envolvidos e no desenvolvimento sustentável da comunidade, bem como o fortalecimento da agricultura agroecológica da comunidade.
\end{abstract}

PALAVRAS-CHAVE: Banco de proteína; Extensão rural; Alimentação animal.

\section{CONTEXTO}

O banco de proteína tem a finalidade de armazenar alimento com diversas leguminosas, elevado valor proteico durante o ano todo, proporcionando ao produtor suprir seu rebanho quando necessário, para melhorar o ganho de peso. E durante a seca o seu consumo pode aumentar se a oferta da gramínea for baixa (BARCELLOS et al., 2001 apud GONÇALVES, 2017). O banco de proteína pode ser formado por diversas leguminosas, como por exemplo, feijãoguandu (Cajanus cajan), gliricidia (Gliricidia sepium), moringa (Moringa oleífera), mucuna preta (Mucuna pruriens), etc., principalmente as leguminosas resistentes à seca, tem elevado teor proteico, produz forragens e tem boa recuperação de solo.

De acordo com Volpe (2015), para a escolha da espécie a ser utilizada, é necessário que os possíveis compostos tóxicos presentes na composição da planta, estejam em níveis toleráveis para a alimentação dos animais. Várias plantas indicam toxinas que podem causar danos aos animais.

Segundo Moreira (2015), a gliricidia (Gliricidia sepium) é uma leguminosa arbórea perene originada da América Central; é resistente à seca; o plantio pode ser feito por mudas, por sementes ou por estaquia; tem bom valor proteico, variando de $20 \%$ a $30 \%$ de proteína bruta, que pode ser consumida por bovinos, ovinos, suínos, caprinos, aves e coelhos.

O feijão guandu é uma leguminosa arbustiva anual ou semiperene, sua produtividade é considerada elevada, podendo chegar a 12 toneladas por hectare ano. Possui alto valor nutritivo para o gado de leite e/ou corte, sendo sua farinha excelente para a suplementação de suínos e aves. As folhas e ramos finos apresentam teores de proteína bruta entre 16 e $20 \%$ (AZEVEDO, 2007).

Este trabalho teve como objetivo contribuir com a implantação de um banco de proteína com leguminosas de alto valor nutritivo para alimentação animal e no intuito de fortalecer a agricultura familiar na comunidade do Amaragi - Lagoa Seca - PB.

\section{DESCRIÇÃO DA EXPERIÊNCIA}

A pesquisa foi realizada na comunidade do Amaragi, situada na zona rural de Lagoa Seca - PB, há $7 \mathrm{~km}$ do centro da referida cidade, junto com a participação de 05 (cinco) famílias que residem no local. A ação foi iniciada no mês de maio até o mês de junho de 2019, onde foi realizado os manejos necessários, foi realizado a capina e o coroamento das leguminas com cobertura morta dentro da unidade do banco de proteína.

Nossa primeira visita aconteceu no dia 18/05/2019, foi uma atividade onde constituiu na observação criteriosa realizada pelos próprios alunos da Universidade Estadual da Paraíba - Campus II e participantes do projeto a princípio do que iria ser feito. Ao chegarmos na propriedade tivemos uma reunião e discutimos o que deveria ser feito, depois nos dirigimos para a área do projeto do banco de proteína, que tem por intuito de trabalhar em uma área de terra cultivada com leguminosa de elevado potencial de produção e qualidade de forragem. O banco de proteína pode ser formado, principalmente com as leguminosas resistentes à seca, as áreas cultivadas com leguminosas podem suprir as necessidades de proteína para bovinos, caprinos e aves caipiras.

O sistema de irrigação por gotejamento foi instalado anteriormente por participantes e colaboradores do projeto. Foi feita a demarcação das culturas que não se desenvolveram para que fossem replantadas em outro momento com espaçamento de uma cultura para outra aproximadamente de $2 \mathrm{~m}$ entre plantas e fileiras, assim promovendo um bom 
SANTOS, V. G. et al. Banco de Proteína: Fortalecimento da Agricultura Familiar na Comunidade do Amaragi no Município de Lagoa Seca-Paraíba. In: II Congresso Paraibano de Agroecologia \& IV Exposição Tecnológica, 2019. Anais... Caderno Verde de Agroecologia e Desenvolvimento Sustentável, Pombal, v. 9, n.7, e-6990, 2019.

crescimento e para que não haja competição por espaço. Foi realizado o coroamento nas culturas que já estavam desenvolvidas, após ser realizado o coroamento nas plantas, foi colocada cobertura morta, que é uma prática benéfica para os produtores na qual evita a degradação do solo, a evapotranspiração e a infestação de plantas espontâneas. $\mathrm{O}$ preparo da cobertura morta foi realizado pela mistura entre restos vegetais e esterco bovino, essa mistura ficou armazenada em um local aberto e sombreado durante o período de três meses, pra obtenção de uma biomassa rica em nutrientes. Após esse período a cobertura foi colocada no solo dando prioridade as culturas que já estavam desenvolvidas como o feijão Guandu (Cajanus cajan (L.) Millsp.) e Gliricidia (Gliricidia sepium (Jacq) Walp.), que são leguminosas consideradas plantas melhoradoras do solo, beneficiando os atributos químicos, físicos e biológicos do solo por meio de folhas e decomposição de raízes e também rico em proteína para à alimentação animal (VOLPE; CARDOSO, 2015) (Figura 01).

A segunda visita foi realizada no dia 29/05/2019, ao chegamos na comunidade do Amaragi, compartilhamos um café da manhã e logo após seguimos para a área do projeto que dividimos em dois grupos. O grupo 1 se destinou a comunidade composta por aproximadamente 40 famílias, com o intuito de convidá-las para a oficina sobre Banco de Proteína, que foi realizada no dia 01/06/2019, na propriedade "Nosso Sitio" localizada na comunidade do Amaragi. A oficina foi ministrada pela bolsista do projeto Bruna dos Santos Souza junto com sua orientadora, e contou com a presença de 04 famílias.

O grupo 2 se dirigiu para a área do projeto onde foi realizado a capina para incorporação da matéria orgânica e controle das ervas espontâneas (Figura 02).

Figura 01. Coroamento com cobertura morta no feijão guandu.

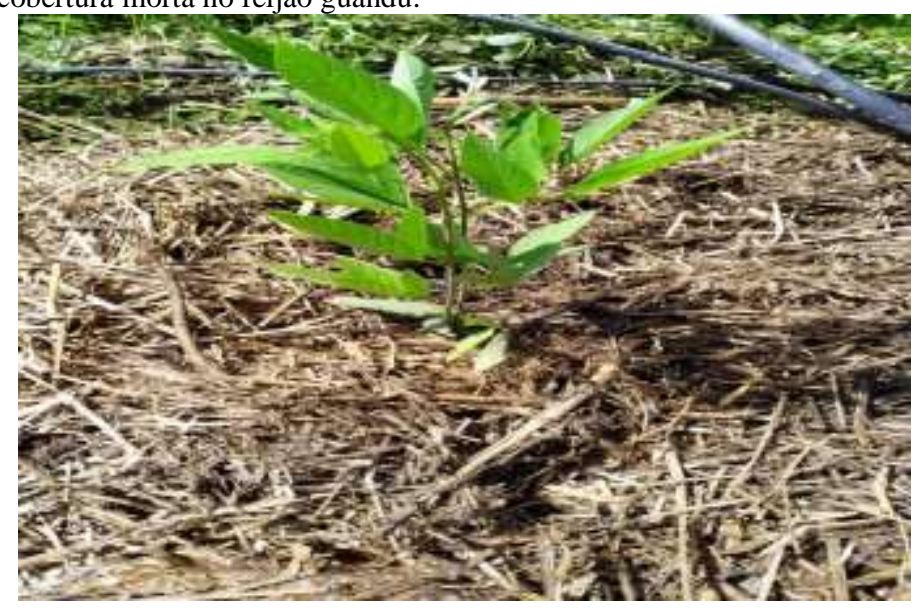

Figura 02. Limpeza da área realizada por alunos da UEPB/Campus II.

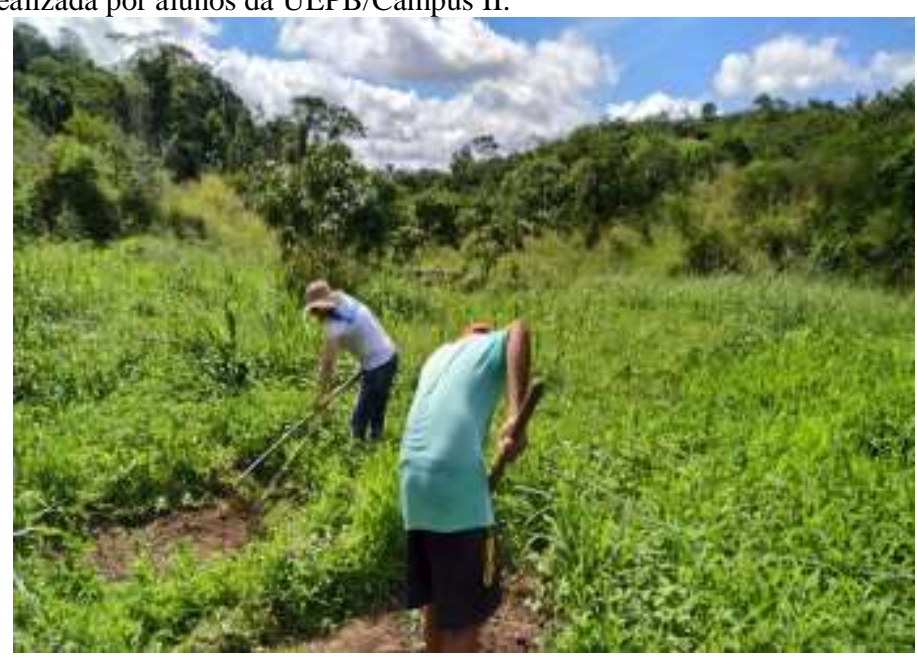

\section{RESULTADOS}

Por meio da ação da extensão universitária, que tem como característica a troca de saberes entre a universidade e a comunidade, percebe-se a relevância da realização de trabalhos como este, como forma de aprendizado e como ponto de partida para encorajar alunos e moradores da comunidade a aplicarem esta experiência em suas propriedades, que servirá como uma alternativa viável de reestruturação ambiental.

A vivência dessa atividade constituiu numa estratégia que foi centralizada na aprendizagem dos alunos envolvidos e no desenvolvimento sustentável da propriedade. E também alguns aspectos relevantes de sua implantação 
SANTOS, V. G. et al. Banco de Proteína: Fortalecimento da Agricultura Familiar na Comunidade do Amaragi no Município de Lagoa Seca-Paraíba. In: II Congresso Paraibano de Agroecologia \& IV Exposição Tecnológica, 2019. Anais... Caderno Verde de Agroecologia e Desenvolvimento Sustentável, Pombal, v. 9, n.7, e-6990, 2019.

de um banco de proteína como fonte de nutriente para a alimentação animal e sua importância agroecológica para a agricultura familiar.

\section{REFERÊNCIAS}

AZEVEDO, R. L.; RIBEIRO, G. T.; AZEVEDO, C. L. L. Feijão-guandu: uma planta multiúso. Revista da Fapese, v. 3, n. 2, p. 81-86, 2007.

BARCELLOS, A. O.; ANDRADE, R. P.; ZOBY, J. L. F.; VILELA, L. Bancos de proteína de Stylosanthes guianensis $c v$ Mineirao: maneira simples de baixo custo para fornecer proteína ao gado na seca. Embrapa Cerrados-Circular Técnica (INFOTECA-E), 2001.

GONÇALVES, F. G. Produção e composição do leite de vacas suplementadas em banco de proteínas composto pela Stylosanthes guianensis cv. BRS Bela. 2017. 36p. Monografia (Curso de Medicina Veterinária) - Faculdade de Agronomia e Medicina Veterinária, Universidade de Brasilia, Brasilia 2017.

MOREIRA, J. N.; BRANDAO, W. N.; CORREIA, R. C. Gliricídia: Banco de Proteína para a Suplementação de Caprinos e Ovinos no Período Seco do Ano. 2015. Disponível em: <http://www.infoteca.cnptia.embrapa.br/infoteca /handle/doc/1017070>. Acesso em: 19 de set 2019.

VOlPe, E.; CARDOSO, S. Bancos de Proteína para a pecuária leiteira. Centro de Pesquisa e Capacitação da Agraer - Cepaer - Campo Grande-MS, 2015.

\section{AGRADECIMENTOS}

Apoio financeiro: Fundação de Apoio à Pesquisa do Estado da Paraíba - FAPESQ. 